\title{
Planificación de menú para adultos con diabetes ${ }^{1}$
}

\author{
Nancy J. Gal y Wendy J. Dahl; traducción por Daniela Rivero Mendoza²
}

La nutrición, la actividad física y la medicación son los tres componentes principales de un plan de manejo de la diabetes. Según la Asociación Americana de Diabetes, no existe un plan específico de comidas para la diabetes. Si tiene diabetes, es importante desempeñar un papel activo en su autocontrol diario. Al trabajar con un Dietista Nutricionista Registrado (RDN), preferiblemente uno que sea un educador certificado en diabetes (CDE), puede desarrollar un plan de nutrición personalizado basado en sus objetivos de tratamiento, medicamentos y preferencias personales.

\section{Objetivos principales del manejo de la nutrición}

$\checkmark$ Lograr objetivos individualizados de tratamiento de la diabetes relacionados con A1C (un análisis de sangre, sin necesidad de ayuno, que mide el promedio de glucosa en sangre en los últimos dos o tres meses), glucosa en sangre, presión arterial, grasa en sangre y peso corporal.

$\checkmark$ Prevenir o retrasar el desarrollo o la gravedad de las complicaciones de la diabetes.

$\checkmark$ Promover patrones de alimentación saludable que consisten en cantidades apropiadas de alimentos ricos en nutrientes.

$\checkmark$ Proporcionar sugerencias prácticas e individualizadas para la planificación diaria de comidas.

$\checkmark$ Mejorar la salud a través de una nutrición óptima.

\section{Creando su plan de comidas personalizado}

Existen muchos patrones de alimentación saludable adecuados para controlar la diabetes. La mejor opción es un patrón de alimentación que pueda seguir para cumplir con sus objetivos de tratamiento individualizados, preferencias personales y presupuesto. Algunos ejemplos de patrones de alimentación aceptables incluyen el enfoque de alimentación al estilo mediterráneo, el enfoque dietético para detener la hipertensión (DASH), la alimentación baja en carbohidratos y la dieta basada en plantas.

\section{Considere estos factores al crear su plan de comidas}

- Grasas en sangre

- Glucosa en sangre

- Presión arterial

- Peso corporal

- Presupuesto y disponibilidad de alimentos

- Actividad física

- Cultura

- Preferencias de alimentación

- Estilo de vida

- Medicación

- Estado de salud general

1. Este documento, FSHN19-3s, es uno de una serie de publicaciones del Departamento de Ciencias de la Alimentación y Nutrición Humana, Servicio de Extensión Cooperativa de la Florida, Instituto de Alimentos y Ciencias Agrícolas, Universidad de la Florida (UF/IFAS Extension). Fecha de primera publicación: abril 2020. Visite nuestro sitio web EDIS en https://edis.ifas.ufl.edu.

2. Nancy J. Gal, Extension agent IV, food and consumer sciences, UF/IFAS Extension Marion County, Ocala, FL; and Wendy J. Dahl, associate professor, Food Science and Human Nutrition Department, UF/IFAS Extension, Gainesville, FL 32611. Traducción por Daniela Rivero Mendoza.

The Institute of Food and Agricultural Sciences (IFAS) is an Equal Opportunity Institution authorized to provide research, educational information and other services

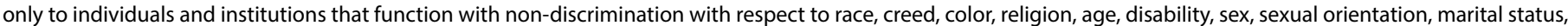

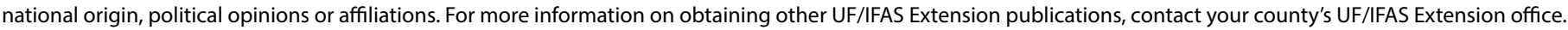
U.S. Department of Agriculture, UF/IFAS Extension Service, University of Florida, IFAS, Florida A \& M University Cooperative Extension Program, and Boards of County Commissioners Cooperating. Nick T. Place, dean for UF/IFAS Extension. 


\section{Practique comportamientos de alimentación saludable}

Consuma las calorías adecuadas para lograr y mantener un peso saludable.

$\checkmark$ Elija alimentos con cantidades más bajas de grasa total, grasas saturadas, sodio y azúcares agregados.

$\checkmark$ Coma una variedad de alimentos ricos en nutrientes y fibra.

$\checkmark$ Disfrute de los dulces con moderación.

Concéntrese en vegetales sin almidón.

Distribuya distanciadamente las comidas y las fuentes de alimentos con carbohidratos durante todo el día.

\section{El Método del Plato de la}

\section{Asociación Americana de Diabetes}

El Método del Plato de la Diabetes es una estrategia de planificación de comidas que es muy efectiva para controlar el consumo de carbohidratos y las calorías sin tener que pesar o medir los alimentos. La cantidad de carbohidratos que consume se basa en su plan de tratamiento y la tolerancia a los carbohidratos.

Todo lo que necesita es un plato de 9 pulgadas más un tazón pequeño y un vaso de bebida para colocar los alimentos de cada uno de los cinco grupos de alimentos: proteínas magras, almidón, vegetales sin almidón, frutas y lácteos (Ver Figura 1). Divida visualmente su plato en secciones para vegetales sin almidón, almidón y alimentos con proteínas magras. El tazón pequeño es para fruta. El vaso de bebida es para leche o yogurt. La clave es seleccionar alimentos saludables de cada uno de los cinco grupos de alimentos para crear su plato "saludable".

Las secciones del plato controlarán los tamaños de las porciones para ayudar a controlar las calorías y los carbohidratos en cada comida. Usted también deberá tener en cuenta la elección de alimentos con bajo contenido de grasas, especialmente grasas saturadas, sodio y azúcares añadidos.

Dado que las necesidades dietéticas de cada persona son diferentes, es importante consultar con un RDN, preferiblemente un CDE, para determinar sus necesidades diarias de calorías y cuántas opciones de cada uno de los cinco grupos de alimentos necesita en cada comida y refrigerio (tentempié o merienda).

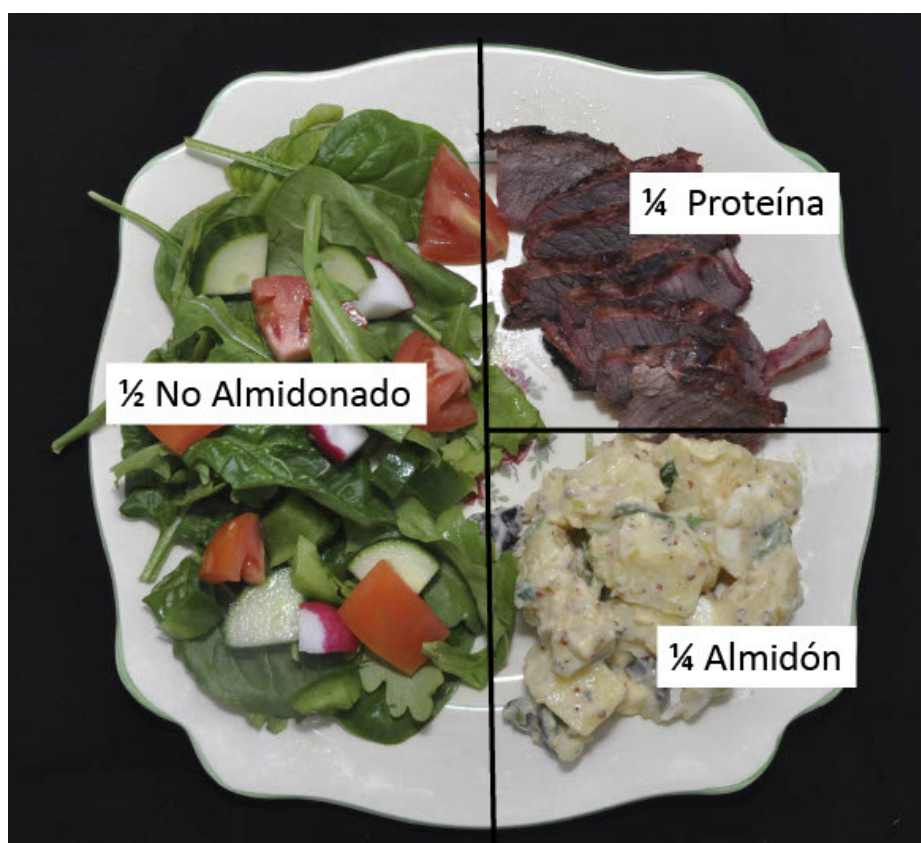

Figura 1. Ejemplo del Método del Plato de Diabetes (Filet Mignon con ensalada de papas Dijon y ensalada mixta).

Credits: Lincoln Zotarelli, UF/IFAS

Asegúrese de consultar con su proveedor de atención médica antes de realizar cambios en su plan de tratamiento de la diabetes.

Haga clic en http://www.diabetesforecast.org/2015/adm/ diabetes-plate-method/what-is-the-plate-method.html para visitar el sitio web de la Asociación Americana de Diabetes para obtener más información sobre el manejo de la nutrición para adultos con diabetes. 